\title{
Potential Impact of the New American High Blood Pressure Guidelines on Hypertension Prevalence in a Primary Health Care Unit in Rio de Janeiro - the LapARC Study
}

Marcelle Guimarães de Oliveira, ${ }^{\circledR}$ Angélica Furriel de Almeida da Silva, ${ }^{2}{ }^{\circledR}$ Taissa Lorena dos Santos, ${ }^{2}$ Mariana Loureiro Cunha, ${ }^{2}{ }^{\circledR}$ Bruna Rosenbrock Ferreira Taveira, ${ }^{\circledR}{ }^{\circledR}$ Elizabeth Silaid Muxfeldt ${ }^{2,3}{ }^{\circledR}$

Universidade Federal do Estado do Rio de Janeiro, Escola de Medicina e Cirurgia, Hospital Universitário Gafree e Guinle, ${ }^{\prime}$ Rio de Janeiro, RJ - Brazil. Universidade Estácio de Sá, Curso de Medicina Campus Presidente Vargas, Estudo LapARC, ${ }^{2}$ Rio de Janeiro, RJ - Brazil.

Universidade Federal do Rio de Janeiro, Faculdade de Medicina, Hospital Universitário Clementino Fraga Filho, ProHArt, ${ }^{3}$ Rio de Janeiro, RJ - Brazil

\section{Abstract}

Background: The new American Heart Association guidelines for hypertension (HT) proposed a reduction of the diagnostic cut-off point, leading to a substantial increase in the prevalence of HT.

Objectives: To assess the prevalence of HT determined by the traditional criteria, the AHA criteria, and home blood pressure monitoring (HBPM) in a population of young adults attending a primary healthcare unit, and its association with cardiovascular risk.

Methods: A cross-sectional population study on adults aged from 20 to 50 years attending a primary healthcare unit, in Rio de Janeiro, Brazil. Sociodemographic and anthropometric data, cardiovascular risk factors, office blood pressure and HBPM were registered. The diagnosis of HT was defined by traditional criteria (office BP $\geq 140 \times 90$ $\mathrm{mmHg}$ ) and by the new (AHA) criteria (office $\mathrm{BP} \geq 130 \times 80 \mathrm{mmHg}$ ). Bivariate analysis was used for comparisons between the two diagnostic criteria, and Kappa coefficient was used to assess the agreement in diagnosis between office BP and HBPM. The level of significance adopted was $5 \%(\mathrm{p}<0.05)$.

Results: A total of 472 individuals were evaluated (male: 39\%; mean age: $38.5 \pm 8.7$ years). The prevalence of HT was $23.5 \%$ and raised to $41.1 \%$ with the new AHA criteria. The prevalence of HT using HBPM was $25.5 \%$, but the diagnostic agreement was low (kappa $=0.028$ ) with changes in diagnosis in $18 \%$ of the cases.

Conclusion: The prevalence of HT almost doubled with the new AHA diagnostic criteria for HT. HBPM seemed to be an important instrument in HT diagnosis in this population. (Int J Cardiovasc Sci. 2021; 34(3):284-293)

Keywords: Cardiovascular Diseases; Hypertension/diagnosis; Blood Pressure; Epidemiology; Primary Health Care.

\section{Introduction}

Hypertension (HT) is usually diagnosed as office blood pressure (BP) equal to or higher than $140 \times 90 \mathrm{mmHg} .{ }^{1,2}$ However, the new American Heart Association (AHA) guidelines recommended to reduce the diagnostic cut-off point for hypertension to $\geq 130 \times 80 \mathrm{mmHg}$, leading to an increase in hypertension prevalencec. ${ }^{3}$ Based on this, it is estimated that half of the general population would be considered hypertensive, with greater inclusion of young individuals. It is not clear, however, whether this will bring benefits in terms of leading to lifestyle changes and preventing cardiovascular (CV) events, or if it will simply increase the consumption of anti-hypertensive drugs. The new guidelines also reinforce the importance of blood pressure measurements outside the office, using Ambulatory Blood Pressure Monitoring (ABPM) or Home Blood Pressure Monitoring (HBPM) $\cdot^{1-3}$

The LapARC study is a population cohort study that aims to evaluate and compare the prevalence of HT using the traditional criteria, the new AHA guidelines, and HBPM, as well as its association with $\mathrm{CV}$ risk in this population.

\section{Methods}

This is a cross-sectional population study of a cohort of 472 adults (20-50 years of age), selected from a total of 1,100

Mailing Address: Elizabeth Silaid Muxfeldt

Rua Homem de Melo, 150/102. Postal Code: 20510-180, Tijuca, Rio de Janeiro - RJ, Brazil.

E-mail: bethmux@globo.com 
patients (43\%) enrolled in CSE-Lapa, a school-based primary health center in Rio de Janeiro, Brazil.

\section{Data Collection}

In the first evaluation, sociodemographic characteristics (gender and age), physical inactivity (regular physical activity < 150 minutes/week), smoking (current smoking of at least one cigarette a day), previous diagnosis of hypertension, diabetes and dyslipidemia (total cholesterol > $190 \mathrm{mg} / \mathrm{dL}$, LDL-cholesterol > $115 \mathrm{mg} / \mathrm{dL}$, HDL-cholesterol $<40 \mathrm{mg} / \mathrm{dL}$ in men and $<46 \mathrm{mg} / \mathrm{dL}$ in women, triglycerides $>150 \mathrm{mg} / \mathrm{dL}$ or use of statin) were registered. ${ }^{1,2}$ To assess obesity, the following anthropometric measurements were taken: weight and height for calculating Body Mass Index (BMI), abdominal circumference (midpoint between the lower costal margin and the iliac crest) and neck circumference (at the level of the cricothyroid cartilage) ${ }^{1,2}$ The cut-off point used to assess obesity was BMI $\geq 30 \mathrm{~kg} / \mathrm{m}^{2}$. For abdominal obesity, we considered an abdominal circumference $\geq$ $88 \mathrm{~cm}$ in women and $\geq 102 \mathrm{~cm}$ in men, and for increased neck circumference, we used $>41 \mathrm{~cm}$ in women and $>$ $43 \mathrm{~cm}$ in men. ${ }^{1,2}$

\section{Blood Pressure Measurements}

Office BP was measured using a digital oscillometric device (MicrolifeWatch BP03) ${ }^{4}$ with a cuff suitable for the arm circumference, following the Brazilian Society of Cardiology guidelines. ${ }^{2}$ The average readings obtained from two measurements was considered for analysis. The ankle-brachial index (ABI) was also calculated, as the ratio between the highest systolic BP taken from the lower limb to the highest systolic BP taken from the upper limb; an $\mathrm{ABI} \geq 0.9$ was considered normal. ${ }^{1,2}$ The diagnosis of HT was defined by traditional criteria - office $B P \geq 140 x$ $90 \mathrm{mmHg}^{1,2}$ - and the new AHA criteria - office BP $\geq 130$ x $80 \mathrm{mmHg}$, considering stage I, a systolic BP between 130 and $139 \mathrm{mmHg}$ and diastolic BP between 80 and 89 $\mathrm{mmHg}$, and stage II $\geq 140 \times 90 \mathrm{mmHg}^{3}$

Individuals were considered hypertensive when they previously knew their diagnosis (taking antihypertensive drugs or not) and had increased average office BP in two visits.

A subgroup of 218 individuals who were not using anti-hypertensive drugs underwent HBPM (HEM705 CP, Omron Healthcare, Kyoto, Japan $)^{5}$, which is considered the gold standard for the diagnosis of
HT. A 7-day protocol, with four daily measurements (two in the morning and two in the afternoon), was used. ${ }^{6}$ The measurements taken on the first day were discarded and the average of the remaining six days was used in the analysis. Normal BP was defined as $<135 \times 85 \mathrm{mmHg}$, following the Brazilian Guidelines on hypertension (traditional criteria). ${ }^{2,6}$ Based on office BP and HBPM, individuals were classified in four phenotypes: (i) normotension with controlled office BP and HBPM, (ii) sustained HT with uncontrolled office BP and uncontrolled HBPM, (iii) white coat HT (WCHT) with increased office BP and controlled HBPM, and (iv) masked hypertension (MHT) with normal office BP and uncontrolled HBPM.

\section{Electrocardiography (ECG)}

Individuals underwent resting ECG to calculate voltage indexes for the diagnosis of left ventricular hypertrophy (LVH). The Solokow index was calculated by the formula SV1 + RV5 (cohort value $\geq 35 \mathrm{~mm}$ ) and the Cornell index by RaVL + SV3 ( $\geq 20 \mathrm{~mm}$ to women and $\geq$ $28 \mathrm{~mm}$ to men). ${ }^{1,2}$

\section{Statistical Analysis}

The statistical analysis was made using the SPSS 19.0 (SPSS, Chicago, IL). Since it was a population study, a convenience sample was used. Data normality was verified using a histogram and a quantile-quantile (Q-Q) plot. Continuous variables showed normal distribution and were described as mean and standard deviation (SD). Bivariate analysis was used in the analysis of HT diagnosis by traditional criteria and by the new AHA guidelines, and comparisons were performed by unpaired Student's $t$ test (continuous variables with normal distribution) and the $\chi 2$ test (categorical variables). The prevalence of the four hypertension phenotypes (normotension, sustained HT, WCHT and MHT) was calculated, and the agreement in HT diagnosis between the two methods was assessed by Kappa coefficient. One-Way ANOVA was used to evaluate differences in continuous variables between different groups, with $\mathrm{p}$ value calculated in relation to the normotensive group. The significance level adopted was $5 \%(\mathrm{p}<0.05)$.

The variables sex, age $>39$ years (mean age of the population), obesity, increased neck circumference, smoking, physical inactivity and the Sokolow-Lyon and Cornell indexes were examined in a multiple logistic regression model, and the HT diagnostic criteria (traditional 
criteria, new AHA criteria and HBPM) were used as dependent variables. A step-by-step procedure was used to select the independent covariables (variables with $\mathrm{p}<$ 0.10 were selected to be added and remain in the models). The Hosmer-Lemeshow goodness-of-fit test and the area under the ROC curve were used to assess calibration and discrimination of the models. The results were presented as odds ratio (OR) and 95\% confidence interval (CI).

Ethical considerations: The study was approved by the Research Ethics Committee of the institution and all participants signed an informed consent form.

\section{Results}

A total of 472 individuals were assessed; 186 (39\%) were male, and mean age was $38.5 \pm 8.7$ years. Seventyone $(15 \%)$ patients reported previous diagnosis of hypertension, of which $62(87 \%)$ were under pharmacological treatment, and 37 (52\%) had good blood pressure control.

According to the traditional criteria, 109 (23\%) individuals were considered hypertensive (stage II), and 192 individuals (41\%) were hypertensive using the new criteria (stage I). These 83 "new" hypertensive patients according to the AHA criteria, were mostly men, less sedentary, with increased neck circumference (Table 1). When compared with stage II hypertensive patients $(\mathrm{n}=109)$, stage I hypertensive subgroup was younger (38.3 \pm 9.2 vs $43.0 \pm 8.1$ years; $p<0.001$ ), had a lower prevalence of abdominal obesity ( $27 \%$ vs $59 \%$; p < 0.001 ) and physical inactivity (27\% vs 59\%; p = 0.04), and lower BMI, neck circumference and Sokolow and Cornell indexes. They also had a lower (but not statistically significant) ABI compared with normotensive individuals (Table 2).

The prevalence of hypertension diagnosed by HBPM was $25.7 \%(n=56)$. Despite the similarity between the prevalence rates for office BP (23.1\%) and for HBPM $(25.7 \%)$, the diagnostic agreement was very low (Kappa coefficient $=0.028$ ). In HBPM, we identified 167 normotensive individuals, 13 with sustained hypertension, 18 with WCHT and 20 with MHT. Therefore, in $17.5 \%$ of the cases $(n=38)$, the diagnosis of HT changed with HBPM (Figure 1).

Individuals with WCHT were mostly men, had greater neck circumference and an increased Cornell index as compared with normotensive subjects. These patients showed not only increased office BP, but also increased home BP compared with normotensive individuals. Compared with sustained HT patients, individuals with WCHT had a lower BMI $\left(28.1 \pm 3.9\right.$ vs $30.9 \pm 3.2 \mathrm{~kg} / \mathrm{m}^{2}$,

Table 1 - Baseline characteristics of the total population and of normotensive and hypertensive groups according to the American Heart Association (AHA) and the traditional diagnostic criteria for hypertension

\begin{tabular}{|c|c|c|c|c|}
\hline Characteristics & $\begin{array}{c}\text { Total } \\
\text { population } \\
(\mathrm{n}=472)\end{array}$ & $\begin{array}{l}\text { Normotension } \\
\quad(n=280)\end{array}$ & $\begin{array}{c}\text { Hypertension by } \\
\text { AHA }^{\mathrm{a}}(\mathrm{n}=83)\end{array}$ & $\begin{array}{l}\text { Hypertension by } \\
\text { traditional criteria }{ }^{\mathrm{b}} \\
\qquad(\mathrm{n}=109)\end{array}$ \\
\hline Male, $n(\%)$ & $186(39.4)$ & $81(28.9)$ & $45(54.2) \ddagger$ & $60(55.0) \ddagger$ \\
\hline Obesity, $\mathrm{n}(\%)^{1}$ & $115(24.4)$ & $51(18.2)$ & $19(22.9)$ & $45(41.3) \ddagger$ \\
\hline Abdominal obesity, $\mathrm{n}(\%)^{2}$ & $177(37.5)$ & $91(32.5)$ & $22(26.5)$ & $64(58.7) \ddagger$ \\
\hline Increased neck circumference, $\mathrm{n}(\%)^{3}$ & $53(11.2)$ & $12(4.3)$ & $9(10.8) *$ & $32(29.4) \ddagger$ \\
\hline Diabetes, $\mathrm{n}(\%)$ & $16(3.4)$ & $4(1.4)$ & $3(3.6)$ & $9(8.3)+$ \\
\hline Physical inactivity, $\mathrm{n}(\%)$ & $206(43.6)$ & $127(45.4)$ & $27(32.5) *$ & $52(47.7)$ \\
\hline Smoking, $\mathrm{n}(\%)$ & $68(14.4)$ & $39(13.9)$ & $16(19.3)$ & $13(11.9)$ \\
\hline Dyslipidemia, $\mathrm{n}(\%)$ & $85(18.0)$ & $47(16.8)$ & $12(14.5)$ & $26(23.9)$ \\
\hline \multicolumn{5}{|c|}{$\begin{array}{l}{ }^{a} \text { AHA criteria }(B P \geq 130 \times 80 \mathrm{mmHg}) ;{ }^{b} \text { traditional criteria }(B P \geq 140 \times 90 \mathrm{mmHg}) \\
{ }^{1} \text { Obesity: } B M I>30 \mathrm{~kg} / \mathrm{m}^{2} \\
{ }^{2} \text { Abdominal obesity }- \text { increased abdominal circumference: }>88 \mathrm{~cm} \text { in women and }>102 \mathrm{~cm} \text { in men } \\
{ }^{3} \text { Increased neck circumference: }>41 \mathrm{~cm} \text { in women and }>43 \mathrm{~cm} \text { in men } \\
\text { Values are averages }(S D) \text { or absolute numbers and percentages, } \\
\chi^{2} \text { test }-p \text { value calculated in relation to reference group (normotension) } \\
{ }^{*} p<0.05 ; \dagger p<0.01 ; \neq p<0.001\end{array}$} \\
\hline
\end{tabular}




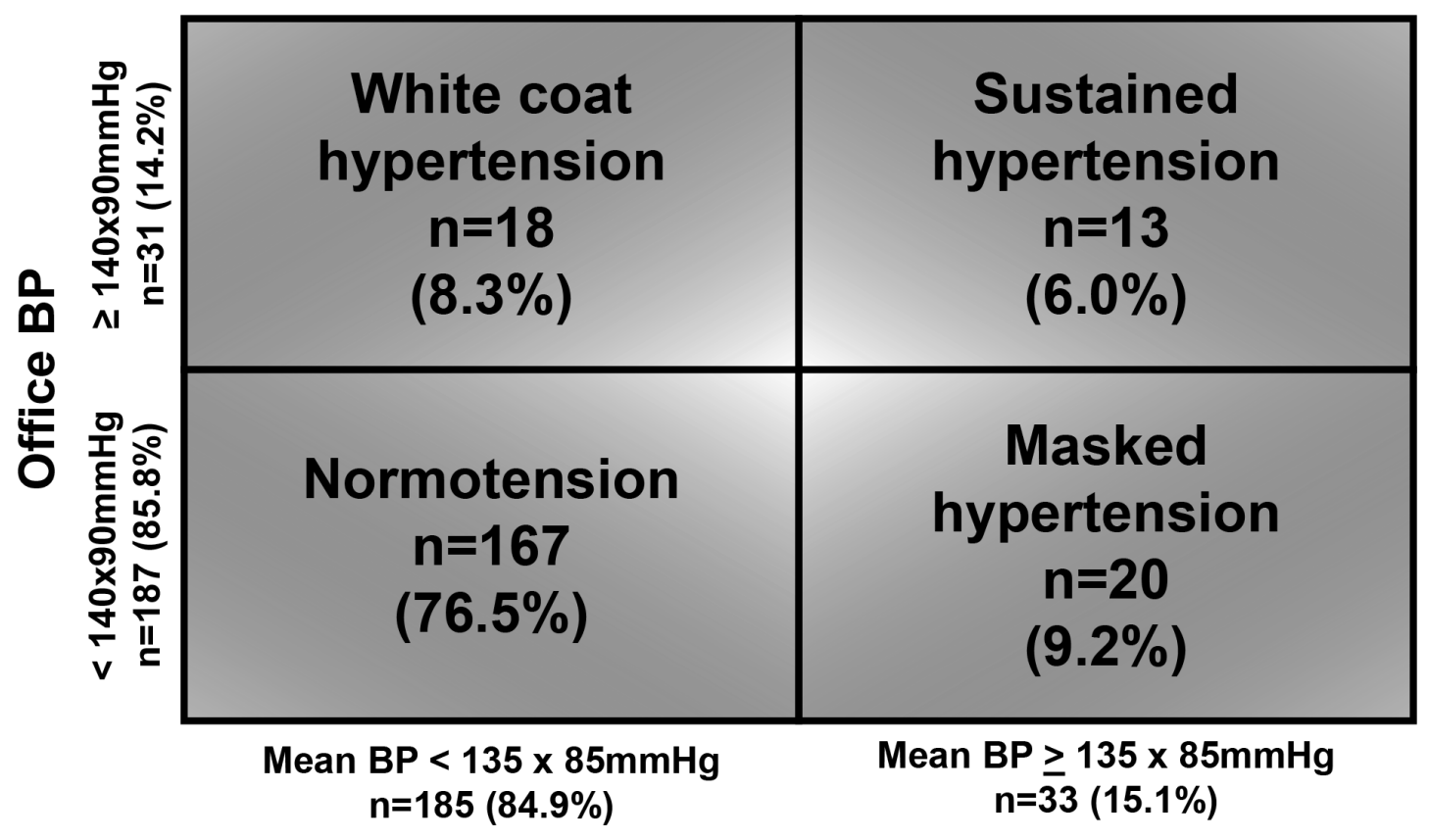

HBPM

Figure 1 - Distribution of phenotypes of arterial hypertension diagnosed by office blood pressure (BP) and home blood pressure monitoring (HBPM)

$p=0.03)$. Except for office BP and home BP values, patients with MHT were similar in terms of $\mathrm{CV}$ risk factors compared with patients with sustained HT (Table 3).

In multiple logistic regression, obesity was independently associated with the diagnosis of HT, regardless of the diagnostic criteria, increasing the risk of developing HT by 2 to 3 times, and the only factor associated with the diagnosis of HT by HBPM. Increased neck circumference, male gender and older age were associated with the risk of HT by office BP (Table 4).

\section{Discussion}

The main finding of our study was the increase in the prevalence of $\mathrm{HT}$ from $23 \%$ by the traditional criteria (office BP criteria) to $41 \%$ by the new AHA criteria in a population of young adults. These patients, diagnosed with HT only by the AHA but not by the traditional criteria, have characteristics suggestive of higher CV risk, such as higher neck circumference and higher voltage index on the ECG. Regarding the diagnosis of HT by HBPM, although the prevalence of HT was comparable to that by office $\mathrm{BP}$, the concordance between the two methods was very low, with $18 \%$ of the participants having their diagnosis modified with home BP measurements.

Individuals classified as stage 1 by the new AHA guidelines did appear to have a higher $\mathrm{CV}$ risk compared to normotensive individuals, suggesting that the early diagnosis of this condition, in the context of primary care, in a younger population, may be important to reduce future risks. Studies in different countries have shown that diagnosis, treatment and control of HT are lower among young adults. ${ }^{7,8}$ On the other hand, , when properly assisted and treated, these individuals are more likely to achieve blood pressure control when compared to the elderly. Changes in lifestyle are more feasible and effective in individuals with little endothelial injury and less arterial stiffness, denoting the relevance of the primary prevention strategy. ${ }^{9}$ 


\begin{tabular}{|c|c|c|c|}
\hline Blood pressure stage & $\begin{array}{c}\text { Variables } \\
\text { average }(\mathrm{SD})\end{array}$ & $95 \% \mathrm{CI}$ & p value* \\
\hline \multicolumn{4}{|c|}{ Age, years } \\
\hline Normal $(n=280)$ & $36.6(8.4)$ & $35.6-37.6$ & Reference \\
\hline Stage I $(n=83)$ & $38.3(9.2)$ & $36.2-40.3$ & 0.37 \\
\hline Stage II (n=109) & $43.0(8.1)$ & $41.4-44.5$ & $<0.001$ \\
\hline \multicolumn{4}{|c|}{ Body mass index, $\mathrm{kg} / \mathrm{m}^{2}$} \\
\hline Normal $(n=280)$ & $26.1(4.9)$ & $25.5-26.7$ & Reference \\
\hline Stage I $(\mathrm{n}=83)$ & $27.2(5.2)$ & $26.1-28.4$ & 0.28 \\
\hline Stage II $(\mathrm{n}=109)$ & $29.7(6.0)$ & $28.6-30.9$ & $<0.001$ \\
\hline \multicolumn{4}{|c|}{ Abdominal circumference, $\mathrm{cm}$} \\
\hline Normal (n=280) & $84.4(17.4)$ & $82.3-86.4$ & Reference \\
\hline Stage I $(\mathrm{n}=83)$ & $88.3(15.0)$ & $85.0-91.6$ & 0.17 \\
\hline Stage II (n=109) & $99.6(14.4)$ & $96.8-102.3$ & $<0.001$ \\
\hline \multicolumn{4}{|c|}{ Neck circumference, $\mathrm{cm}$} \\
\hline Normal (n=280) & $34.8(6.2)$ & $34.1-35.6$ & Reference \\
\hline Stage I ( $\mathrm{n}=83)$ & $37.8(3.8)$ & $37.0-38.6$ & $<0.001$ \\
\hline Stage II (n=109) & $39.9(4.4)$ & $39.0-40.7$ & $<0.001$ \\
\hline \multicolumn{4}{|c|}{ Sokolow-Lyon Index, mm } \\
\hline Normal $(n=280)$ & $17.2(5.2)$ & $15.9-18.5$ & Reference \\
\hline Stage I $(\mathrm{n}=83)$ & $20.0(5.7)$ & $17.7-22.3$ & 0.09 \\
\hline Stage II (n=109) & $20.9(5.6)$ & $19.1-22.6$ & 0.004 \\
\hline \multicolumn{4}{|c|}{ Cornell Index, mm } \\
\hline Normal $(\mathrm{n}=280)$ & $10.4(4.1)$ & $9.3-11.4$ & Reference \\
\hline Stage I $(\mathrm{n}=83)$ & $12.7(4.8)$ & $10.8-14.7$ & 0.05 \\
\hline Stage II (n=109) & $13.0(3.9)$ & $11.7-14.2$ & 0.009 \\
\hline \multicolumn{4}{|c|}{ Systolic blood pressure, $\mathrm{mmHg}$} \\
\hline Normal (n=280) & $110(18)$ & $108-113$ & Reference \\
\hline Stage I (n=83) & $127(8)$ & $125-129$ & $<0.001$ \\
\hline Stage II (n=109) & $138(16)$ & $135-141$ & $<0.001$ \\
\hline \multicolumn{4}{|c|}{ Diastolic blood pressure, $\mathrm{mmHg}$} \\
\hline Normal (n=280) & $68(12)$ & $67-69$ & Reference \\
\hline Stage I $(\mathrm{n}=83)$ & $81(5)$ & $79-82$ & $<0.001$ \\
\hline Stage II (n=109) & $85(10)$ & $83-87$ & $<0.001$ \\
\hline \multicolumn{4}{|c|}{ Pulse pressure, $\mathrm{mmHg}$} \\
\hline Normal (n=280) & $42(10)$ & $41-43$ & Reference \\
\hline Stage I (n=83) & $47(11)$ & $44-49$ & 0.004 \\
\hline Stage II $(\mathrm{n}=109)$ & $53(13)$ & $51-55$ & $<0.001$ \\
\hline \multicolumn{4}{|c|}{ Ankle-Brachial Index } \\
\hline Normal (n=280) & $1.15(0.20)$ & $1.12-1.17$ & Reference \\
\hline Stage I $(\mathrm{n}=83)$ & $1.14(0.23)$ & $1.10-1.19$ & 1.00 \\
\hline Stage II (n=109) & $1.11(0.24)$ & $1.06-1.16$ & 0.43 \\
\hline
\end{tabular}


Table 3 - Baseline characteristics of four blood pressure phenotypes, defined by office blood pressure and by home blood pressure monitoring (HBPM)

\begin{tabular}{|c|c|c|c|c|c|}
\hline & $\begin{array}{c}\text { Total } \\
\text { population } \\
(\mathrm{n}=218)\end{array}$ & $\begin{array}{l}\text { Normotension } \\
\quad(n=167)\end{array}$ & $\begin{array}{c}\text { White coat } \\
\text { hypertension } \\
(n=18)\end{array}$ & $\begin{array}{c}\text { Masked } \\
\text { hypertension } \\
(n=20)\end{array}$ & $\begin{array}{c}\text { Sustained } \\
\text { hypertension } \\
(n=13)\end{array}$ \\
\hline \multicolumn{6}{|l|}{ Cardiovascular Risk Factors } \\
\hline Male, $\mathrm{n}(\%)^{\text {a }}$ & $79(36.2)$ & $50(29.9)$ & $14(77.8)^{+}$ & $8(40.0)$ & $7(53.8)$ \\
\hline Age, years ${ }^{b}$ & $39.5(8.2)$ & $39.1(8.2)$ & $39.8(8.4)$ & $40.3(8.3)$ & $43.2(6.6)$ \\
\hline Body mass index, $\mathrm{kg} / \mathrm{m}^{2}$ & $27.6(5.4)$ & $26.9(5.2)$ & $28.1(3.9)$ & $30.8(7.3)+$ & $30.9(3.2)$ \\
\hline Obesity, $\mathrm{n}(\%)^{\text {a }}$ & $45(25.7)$ & $34(20.4)$ & $5(27.8)$ & $10(50.0)+$ & $7(53.0)^{+}$ \\
\hline Abdominal obesity ${ }^{1}, \mathrm{n}(\%)^{\mathrm{a}}$ & $79(36.2)$ & $54(32.3)$ & $7(38.9)$ & $9(45.0) *$ & $9(69.2)^{+}$ \\
\hline Increased neck circumference ${ }^{2}, \mathrm{n}(\%)^{\text {a }}$ & $18(8.3)$ & $7(4.2)$ & $4(22.2) \ddagger$ & $4(20.0) \ddagger$ & $3(23.1) \ddagger$ \\
\hline Diabetes, $\mathrm{n}(\%)^{\text {a }}$ & $9(4.1)$ & $5(3.0)$ & $1(5.6)$ & $1(5.0)$ & $2(15.4)$ \\
\hline Physical inactivity, $\mathrm{n}(\%)^{\text {a }}$ & $101(46.3)$ & $79(47.3)$ & $4(22.2)$ & $11(55.0)$ & $7(53.8)$ \\
\hline Smoking, $\mathrm{n}(\%)^{\text {a }}$ & $26(11.9)$ & $19(11.4)$ & $1(5.6)$ & $3(15.0)$ & $3(23.1)$ \\
\hline Dyslipidemia, n(\%) a & $46(21.1)$ & $36(21.6)$ & $5(27.8)$ & $3(15.0)$ & $2(15.4)$ \\
\hline \multicolumn{6}{|l|}{ Office $\mathrm{BP}, \mathrm{mmHg}$} \\
\hline Systolic BP ${ }^{b}$ & $122(14)$ & $117(10)$ & $144(5) \ddagger$ & $123(13)^{+}$ & $149(10) \ddagger$ \\
\hline Diastolic $\mathrm{BP}^{\mathrm{b}}$ & $74(9)$ & $71(7)$ & $86(7) \ddagger$ & $78(9) \ddagger$ & $90(9) \ddagger$ \\
\hline Pulse pressure ${ }^{b}$ & $47(10)$ & $45(9)$ & $58(10) \ddagger$ & $45(10)$ & $49(10) \ddagger$ \\
\hline \multicolumn{6}{|l|}{ HBPM, mmHg } \\
\hline Systolic BP ${ }^{b}$ & $120(12)$ & $115(9)$ & $125(8) \ddagger$ & $135(9) \ddagger$ & $145(9) \ddagger$ \\
\hline Diastolic $\mathrm{BP}^{\mathrm{b}}$ & $74(9)$ & $71(6)$ & $75(6)^{*}$ & $87(7) \ddagger$ & $88(9) \ddagger$ \\
\hline Pulse pressure $^{b}$ & $46(8)$ & $45(6)$ & $49(7)^{*}$ & $48(9)$ & $57(12) \ddagger$ \\
\hline \multicolumn{6}{|l|}{ Electrocardiogram } \\
\hline Sokolow-Lyon Index $(\mathrm{mV})^{\mathrm{b}}$ & $18.9(5.6)$ & $18.2(5.4)$ & $21.6(4.5)$ & $21.0(7.2)$ & $19.9(6.1)$ \\
\hline Cornell Index $(\mathrm{mV})^{\mathrm{b}}$ & $11.5(4.4)$ & $11.2(4.2)$ & $15.6(3.6)^{+}$ & $9.3(2.8)$ & $12.3(5.3)$ \\
\hline \multicolumn{6}{|c|}{$\begin{array}{l}{ }^{1} \text { Abdominal obesity: increased abdominal circumference: }>88 \mathrm{~cm} \text { in women and }>102 \mathrm{~cm} \text { in men } \\
2 \text { Increased neck circumference: }>41 \mathrm{~cm} \text { in women and }>43 \mathrm{~cm} \text { in men } \\
\text { BP: blood pressure } \\
{ }^{a} \chi 2 \text { test (categorical variables) } \\
{ }^{b} \text { Unpaired Student's t test (continuous variables) } \\
{ }^{*} p<0.05 ;+p<0.01 ; \neq p<0.001, p \text { value calculated in relation to reference group (normotension) }\end{array}$} \\
\hline
\end{tabular}

When shedding light on the new AHA guidelines, it is noted that stage I hypertensive patients were previously labeled "prehypertensive" by the seventh report of the Joint National Committee on prevention, detection, evaluation, and treatment of high blood pressure (JNC7). ${ }^{10}$ This designation aimed to identify individuals at greater risk of developing HT and to intervene early with the adoption of a healthy lifestyle. The term was intended to reduce therapeutic inertia, but paradoxically, less care was delivered..$^{10}$

By reclassifying individuals, the AHA created a disease condition that affects people who were previously considered healthy. It is essential to note that the new definition may result in early diagnosis and prevention, 


\begin{tabular}{|c|c|c|c|}
\hline \multicolumn{4}{|c|}{ HT by traditional criteria $(n=109)$} \\
\hline Cofactors & OR & $95 \% \mathrm{CI}$ & p-value \\
\hline Male & 2.48 & $1.46-4.22$ & 0.001 \\
\hline Increased neck circumference & 3.40 & $1.31-8.81$ & 0.012 \\
\hline Obesity & 2.45 & $1.39-4.30$ & 0.002 \\
\hline Age $>39$ years & 3.77 & $2.18-6.49$ & $<0.001$ \\
\hline \multicolumn{4}{|l|}{ HT by AHA criteria $(n=83)$} \\
\hline Cofactors & OR & $95 \% \mathrm{CI}$ & p-value \\
\hline Male & 3.05 & $1.94-4.81$ & $<0.001$ \\
\hline Increased neck circumference & 3.91 & $1.24-12.4$ & 0.02 \\
\hline Obesity & 2.08 & $1.24-3.49$ & 0.005 \\
\hline Age $>39$ years & 2.23 & $1.44-3.45$ & $<0.001$ \\
\hline \multicolumn{4}{|l|}{ Sustained HT by НВРM (n=13) } \\
\hline Cofactors & OR & $95 \% \mathrm{CI}$ & p-value \\
\hline Male & 1.38 & $0.57-3.33$ & 0.48 \\
\hline Increased neck circumference & 1.65 & $0.45-6.00$ & 0.45 \\
\hline Obesity & 3.07 & $1.28-7.36$ & 0.012 \\
\hline Age $>39$ years & 1.46 & $0.62-3.48$ & 0.39 \\
\hline \multicolumn{4}{|c|}{$\begin{array}{l}\text { Hosmer-Lemeshow goodness-of-fit test: } p=0.604 \text {, area under the ROC curve } 0.791 \text { ( } 95 \% \text { IC } 0.745-0.838 \text { ). } \\
\text { Multiple logistic regression. The model was adjusted for sex, age }>39 \text { years, obesity, increased neck circumference, smoking, physical inactivity, Sokolow- } \\
\text { Lyon e Cornell indices. } \\
\text { HT: hypertension; AHA: American Heart Association; HBPM: Home Blood Pressure Monitoring; OR: Odds Ratio; CI: confidence interval. }\end{array}$} \\
\hline
\end{tabular}

more accurate screening for subclinical lesions and reduction in $\mathrm{CV}$ outcomes. Our study showed that these individuals have higher BMI, greater neck circumference and early changes in voltage indexes on the ECG when compared to normotensive individuals, pointing to a higher $\mathrm{CV}$ risk and greater chances of developing target organ damage, corroborating a possible positive effect in reducing $\mathrm{BP}$ cutoff point for hypertension. ${ }^{3}$ However, these individuals now considered hypertensive (by the AHA criteria) would probably initiate pharmacological therapy earlier, and possibly experience more side effects, leading to higher costs to public health services, ${ }^{11}$ in addition to a progressive reduction in treatment adherence. Vrijens et al., ${ }^{12}$ in a longitudinal study with electronic monitoring of medication, showed that after one year, half of the patients abandoned the pharmacological therapy.
Therefore, it is important to balance risks and benefits for this population. If, on the one hand, pharmacological therapy reduces $\mathrm{CV}$ risk and possible target organ lesions ${ }^{10}$ on the other, it may increase the likelihood of low output syndrome, and make hypertension management difficult. ${ }^{3,11}$

\section{Home Blood Pressure Monitoring}

The increasing importance of HBPM in primary care as a diagnostic and monitoring method for therapeutic response has been studied. ${ }^{13-15}$ Currently, several guidelines $^{1,2}$ suggest that, whenever possible, ABPM or HBPM should be indicated at the time of diagnosis, and the $\mathrm{AHA}^{3}$ recommends that $\mathrm{HT}$ diagnosis be based on elevated office BP followed by confirmatory ABPM or 
HBPM. Compared with ABPM, HBPM is generally more accepted by patients and has a lower cost, ${ }^{6,16}$ in addition to refining the diagnosis and having a higher predictive value of future $\mathrm{CV}$ events than office $\mathrm{BP} ;{ }^{17}$ it is therefore considered a good option for underdeveloped countries. ${ }^{13}$ We emphasize that the use of HBPM in primary care is recommended by the Brazilian Ministry of Health, ${ }^{18}$ although in clinical practice it has not been used due to economic and logistical issues.

In our country, the diagnosis of HT is based on office BP because it is a simple and low-cost procedure, ${ }^{2}$ despite the limitations of this method, especially in individuals with WCHT and MHT. ${ }^{13,19}$ In the present study, despite the similar prevalence of HT diagnosed by office BP and HBPM, the diagnostic agreement was very low and, in almost $20 \%$ of the population, the diagnosis of HT has changed, which corroborates the importance of measuring BP out of the office, including in primary care..$^{13,14,18,20}$

Analyzing individuals with WCHT in our study, we observed that despite normal home BP levels, they seem to present a higher $\mathrm{CV}$ risk associated with greater neck circumference, wider pulse pressure, and early elevation of the Cornell index, although still within normal ranges. Several studies have demonstrated a higher $\mathrm{CV}$ risk and higher risk for HT associated with WCHT. ${ }^{21-23}$ This is in line with our results, which showed that individuals with WCHT have higher (but controlled) home BP levels compared with normotensive individuals (Table 3). They also showed higher Cornell voltage on ECG suggesting $\mathrm{LVH}$, increased neck circumference suggesting a higher risk for obstructive sleep apnea and an increased office pulse pressure and HBPM that may reflect greater arterial stiffness, despite the younger age (Table 3). There is evidence to suggest the need to follow-up this group of patients, regarding lifestyle changes and the possibility of developing sustained hypertension. ${ }^{1-3,9}$

Analysis of MHT patients in our study revealed that, except for office BP, these patients behaved in a similar way to the sustained ones . A meta-analysis of 12 studies with 4,884 untreated individuals, 2,467 of whom were normotensive, 776 patients with MHT and 1,641 patients with sustained hypertension, showed an association between MHT and increased risk of $\mathrm{LVH}^{24}$ In another meta-analysis, the prognosis of individuals with WCHT was similar to that of normotensive individuals, while patients with MHT had a higher prevalence of subclinical lesions such as LVH, carotid wall thickening and microalbuminuria. ${ }^{24}$ In the Finn-Home Study, a progressive increase in the incidence of $\mathrm{CV}$ events and total mortality in normotension, WCHT, MHT and sustained hypertension was observed, ${ }^{25}$ while a recent study showed that individuals with MHT have twice the risk of developing LVH. ${ }^{26}$ Possibly, the difficulty in detecting MHT and consequent lack of treatment contribute to this poor prognosis profile.

In our population, obesity was the common independent risk factor for the diagnosis of HT between the three diagnostic criteria (Table 4). A recent randomized clinical trial developed in several centers in Brazil showed that changes in eating habits had little impact on the secondary prevention of CV events, ${ }^{27}$ but there are no studies demonstrating their long-term effects on reducing obesity and consequently $\mathrm{CV}$ risk.

It is also noteworthy that greater neck circumference increased the odds of having HT by almost four times, regardless of the diagnostic criteria system. Perhaps screening for sleep apnea in a younger population and initiating treatment and instituting treatment at earlier ages may reduce $\mathrm{CV}$ morbidity and mortality in the future; this has not yet been proven in patients with more severe HT and elderly patients using continuous positive airway pressure. ${ }^{28}$

Our study has two main limitations. Our sample was composed of young, economically active individuals, who self-reported as 'healthy'; these individuals do not usually seek health services. Although this group of individuals lived in an area covered by the CSE-Lapa, many were not even registered in the unit, which made it difficult to enroll these subjects in the study. Thus, most of our study population attended the CSE-Lapa, which generated a selection bias. This fact can be confirmed by the mean age of the cohort, which was higher than expected. Another limitation was the predominance of women (61.5\%), apparently related to the well-recognized greater demand for healthcare services by women (including preventive tests, prenatal care etc.), while we know that in this age group $(<50$ years, men have higher $\mathrm{CV}$ risk than women. As it is a study with individuals aged between 20 and 50 years, the conclusions cannot be extrapolated to other age groups.

\section{Conclusion}

As expected, adopting the new AHA criteria caused a significant increase in the prevalence of HT in a population of young adults. However, it is not clear if these individuals would have a higher CV risk, 
pointing to the need for future longitudinal studies. In addition, BP measurements outside the office would be important for a more accurate diagnosis of HT in primary care.

\section{Potential Conflict of Interest}

No potential conflict of interest relevant to this article was reported.

\section{Sources of Funding}

This study was funded by Conselho Brasileiro de Desenvolvimento Científico e Tecnológico (CNPq) and Fundação Carlos Chagas Filho de Amparo à Pesquisa do Estado do Rio de Janeiro (FAPERJ).

\section{Study Association}

This article is part of the thesis of course completion word submitted by Marcelle Guimarães de Oliveira, from Universidade Federal do Estado do Rio de Janeiro.

\section{Ethics Approval and Consent to Participate}

This study was approved by the Ethics Committee of the Universidade Estácio de Sá under the protocol number 50605215.4.0000.5284. All the procedures in this study were in accordance with the 1975 Helsinki Declaration, updated in 2013. Informed consent was obtained from all participants included in the study.

\section{Author Contributions}

Conception and design of the research: Oliveira MG, Almeida da Silva AF, dos Santos TL, Muxfeldt ES. Acquisition of data: Oliveira MG, Almeida da Silva AF, dos Santos TL, Cunha ML, Taveira BRF, Muxfeldt ES. Analysis and interpretation of the data: Oliveira MG, Almeida da Silva AF, dos Santos TL, Muxfeldt ES. Statistical analysis: Muxfeldt ES. Obtaining financing :Muxfeldt ES. Writing of the manuscript: Oliveira MG, Almeida da Silva AF, dos Santos TL, Cunha ML, Taveira BRF, Muxfeldt ES. Critical revision of the manuscript for intellectual content: Oliveira MG, Muxfeldt ES.

\section{References}

1. Williams B, Mancia G, Spiering W, Agabiti Rosei E, Azizi M, Burnier M et al. 2018 ESC/ESH Guidelines for the management of arterial hypertension The Task Force for the management of arterial hypertension of the European Society of Cardiology (ESC) and the European Society of Hypertension (ESH). J Hypertens. 2018; 36(10):1935-2041.

2. Malachias MVB, Souza WKSB, Plavnik FL, Rodrigues CIS, Brandão AA Neves MFT, et al. 7 ${ }^{a}$ Diretriz Brasileira de Hipertensão Arterial. Arq Bras Cardiol 2016; 107(3Supl.3):1-83.

3. Whelton PK, Carey RM, Aronow WS, Casey DE Jr, Collins KJ, Dennison Himmelfarb C et al. 2017 ACC/AHA/AAPA/ABC/ACPM/AGS/APhA/ ASH/ASPC/NMA/PCNA guideline for the prevention, detection, evaluation, and management of high blood pressure in adults: a report of the American College of Cardiology/American Heart Association Task Force on Clinical Practice Guidelines. Hypertension 2018; 71(6):1269-324.

4. Cuckson AC, Reinders A, Shabeeh H, Shennan AH. Validation of the Microlife BP 3BTO-A oscillometric blood pressure monitoring device according to a modified British Hypertension Society protocol. Blood Press Monit 2002; 7(6):319-24.

5. Artigao LM, Llavador JJ, Puras A, López Abril J, Rubio MM, Torres C. Evaluation and validation of Omron Hem 705 CP and Hem 706/711 monitors for self-measurement of blood pressure. Aten Primaria. 2000;25(2):96-102.

6. Nobre F, Mion Júnior D, Gomes MAM, Barbosa ECD, Rodrigues CIS Neves MFT et al. $6^{\text {a }}$ Diretrizes de Monitorização Ambulatorial da Pressão Arterial e $4^{\text {a }}$ Diretrizes Brasileiras de Monitorização Residencial da Pressão Arterial. Sociedades Brasileiras de Cardiologia, Hipertensão e Nefrologia. Arq Bras Cardiol 2018; 110(5 supl1):1-29.

7. Zhang Y, Moran AE. Trends in the Prevalence, Awareness, Treatment, and Control of Hypertension Among Young Adults in the United States, 1999 to 2014. Hypertension. 2017;70(4):736-42.

8. Mosha NR, Mahande M, Juma A, Mboya I, Peck R, Urassa M et al. Prevalence, awareness and factors associated with hypertension in North West Tanzania. Glob Health Action 2017; 10(1):1321279.

9. Precoma DB, Oliveira GMM, Simão AF, Dutra OP, Coelho OR, Izar MCO et al. Atualização da Diretriz Brasileira de Prevenção Cardiovascular da SBC-2019. Arq Bras Cardiol 2019; 113(4):787-891.

10. Verdecchia P, Angeli F. The Seventh Report of the Joint National Commitee on Prevention, evaluation, and treatment of high blood pressure: the weapons are ready. Rev Española de Cardiología, 2003; 56(9):843-7.

11. Bakris G, Sorrentino M. Redefining Hypertension - Assessing the New Blood-Pressure Guidelines. N Engl J Med. 2018; 378(6):497-9.

12. Vrijens B, Vincze G, Kristanto P, Urquhart J, Burnier M. Adherence to prescribed antihypertensive drug treatments: longitudinal study of electronically compiled dosing histories. BMJ 2008; 336(7653):1114-7.

13. Ndip Agbor V, Temgoua MN, Noubiap JJ. Scaling up the use of home blood pressure monitoring in the management of hypertension in lowincome countries: A step towards curbing the burden of hypertension. J Clin Hypertens 2017; 19(8):786-9.

14. Kronish IM, Kent S, Moise N, Shimbo D, Safford MM, Kynerd RE, O'Beirne R, Sullivan A, Muntner P. Barriers to conducting ambulatory and home blood pressure monitoring during hypertension screening in the United States. J Am Soc Hypertens. 2017;11(9):573-80.

15. Abdullah A, Othman S. The influence of self-owned home blood pressure monitoring (HNPM) on primary care patients with hypertension: a qualitative study. BMC Fam Pract. 2011; 12:143.

16. Gosse P, Coulon P. Ambulatory or home measurement of blood pressure? J Clin Hypertens (Greenwich). 2009; 11:234-7. 
17. Bliziotis IA, Destounis A, Stergiou GS. Home versus ambulatory and office blood pressure in predicting target organ damage in hypertension: a systematic review and meta-analysis. J Hypertens. 2012; 30(7):1289-99.

18. Brasil. Ministério da Saúde. Estratégias para o cuidado da pessoa com doença crônica: hipertensão arterial sistêmica. Brasília; 2013. (Cadernos de Atenção Básica, n.37)

19. Alessi A, Brandão AA, Paiva AMG, Nogueira AR, Feitosa A, Gonzaga CC, et al. I Posicionamento Brasileiro sobre Pré-Hipertensão, Hipertensão do Avental Branco e Hipertensão Mascarada: Diagnóstico e Conduta. Arq Bras Cardiol. 2014; 102(2):110-19.

20. Nobre F, Junior DM. Monitorização Ambulatorial da Pressão Arterial: Cinco Décadas de Mais Luzes e Menos Sombras Arq Bras Cardiol. 2016 106(6):528-37.

21. Conen D, Ricker PM, Buring JE, Glynn RJ. Risk of cardiovascular events among women with high normal blood pressure or blood pressure progression: prospective cohort study. BMJ. 2007;335(7617):432-40.

22. Verdecchia P, Reboldi GP, Angeli F, Schillaci G, Schwartz JE, Pickering TG, et al. Short and long-term incidence of stroke in white coat hypertension. Hypertension. 2005;45(2):203-8
23. Mancia G, Bombelli M, Facchetti R, Madotto F, Quarti-Trevano F, Polo Friz $\mathrm{H}$, et al. Long-term risk of sustained hypertension in white-coat or masked hypertension. Hypertension. 2009;54(2):226-32.

24. Pierdomenico SD, Cuccurullo F. Prognostic value of white-coat and masked hypertension diagnosed by ambulatory monitoring in initially untreated subjects: an updated meta-analysis. Am J Hypertens. 2011;24(1):52-8

25. Hanninen MR, Niiranen TJ, Puukka PJ, Johansson J, Jula AM. Prognostic significance of masked and white-coat hypertension in the general population: the Finn-Home Study. J Hypertens. 2012; 30(4):705-12.

26. Cuspidi C, Facchetti R, Quarti-Trevano F, Sala C, Tadic M, Grassi G, Mancia G. Incident Left Ventricular Hypertrophy in Masked Hypertension. Hypertension 2019; 4(1):56-62.

27. Weber B, Bersch-Ferreira ÂC, Torreglosa CR, Marcadenti A, Lara ES, da Silva JT et al. Implementation of a Brazilian Cardioprotective Nutritional (BALANCE) Program for improvement on quality of diet and secondary prevention of cardiovascular events: A randomized, multicenter trial.Am Heart J 2019; 215:187-97.

28. Drager LF, Lorenzi-Filho G, Cintra FD, Pedrosa RP, Bittencourt LR, Poyares D. et. al. $1^{\circ}$ Posicionamento Brasileiro sobre o Impacto dos Distúrbios de Sono nas Doenças Cardiovasculares da Sociedade Brasileira de Cardiologia. Arq Bras Cardiol. 2018; 111(2):290-341. 